\title{
O impacto do desempenho da produtividade do capital para o crescimento econômico nos setores e regiões brasileiras: uma análise de 2002 a $2016 *$
}

\author{
The Impact of Capital Productivity Performance for Economic Growth in \\ Brazilian Sectors and Regions: An Analysis from 2002 to 2016
}

Thais Andreia Araujo de Souza e Marina Silva da Cunha**

\begin{abstract}
Resumo: Este trabalho objetivou estudar a produtividade brasileira entre 2002-2016 e o impacto no crescimento. Esse assunto é importante porque a produtividade é considerada determinante fundamental do crescimento econômico. Para isto, foi estudado o seu desempenho por meio da produtividade de capital e análises setoriais e regionais, buscando verificar onde mais se contribuiu para a baixa produtividade agregada. Ademais, constatado o desempenho da produtividade, foram realizadas decomposições do crescimento para verificar como decorreu a contribuição da produtividade para o crescimento. Dentre os resultados obtidos, se verificou que ocorreu tendência de queda a partir de 2011 na maioria dos setores e regiões, exceto na agropecuária. Portanto, se verifica que o baixo crescimento brasileiro tem se pautado na contribuição baixa da eficiência produtiva.
\end{abstract}

Palavras-chave: Estoque de Capital Fixo; Crescimento Econômico; Nível de Utilização da Capacidade Instalada

\begin{abstract}
This article aimed to study Brazilian productivity between 2002-2016 and the impact on growth. This subject is important because productivity is considered a main determinant of economic growth. To this end, its performance was studied through capital productivity and sectoral and regional analysis, looking to verify where it contributed most to the low aggregate productivity. Furthermore, once the performance of productivity was verified, growth decompositions were performed to verify how the contribution of productivity to growth occurred. Among the results obtained, it was verified that a downward trend occurred starting in 2011 in most sectors and regions, except in agriculture and livestock. Therefore, it is verified that the low Brazilian growth has been based on the low contribution of productive efficiency.
\end{abstract}

Keywords: Fixed Capital Stock; Economic Growth; Level of Capacity Utilization

JEL: D24; H54

\footnotetext{
* Submissão: 28/10/2019 | Aprovação: 20/09/2020 | DOI: 10.5380/re.v42i78.69931

** Respectivamente: (1) Professora colaboradora do Departamento de Economia, Universidade Estadual de Maringá (UEM), Brasil | E-mail: thaisandreiaa@gmail.com | ORCID: 0000-0001-9605-4895 | (2) Professora do Departamento de Economia, Universidade Estadual de Maringá (UEM), Brasil | E-mail: mscunha@uem.br | ORCID: 0000-0001-9122-3944
} 


\section{Introdução}

A produtividade é um tema muito atual no cenário econômico brasileiro. Isto decorreu da preocupação em garantir que a economia crescesse de forma sustentável a longo prazo. Considerando que o crescimento tem diminuído, em média de 4,1\% a.a. no triênio 2008-2010 para 2,0\% a.a. no triênio 2011-2013, e com a crise seguinte, de acordo com Bonelli (2014), surgiu a necessidade de avaliar quais medidas poderiam ser adotadas com o intuito de que o Produto Interno Bruto (PIB) volte a mostrar crescimento contínuo no decorrer dos anos.

Este interesse na produtividade como fator de crescimento econômico decorreu porque, segundo De Negri e Cavalcante (2014), os incentivos ao investimento não tiveram impactos suficientes para estimular a economia brasileira no longo prazo, dada a sua resiliência, e a indústria, que é o motor da economia, tem perdido espaço na composição do PIB para os serviços. Dados os fatos, muitos estudiosos encontraram ou reencontraram na produtividade a solução para voltar a estimular o crescimento econômico. Contudo, conforme afirmaram Squeff e De Negri (2014), a eficiência produtiva brasileira teve desempenho baixo desde o período de 1980, com leve crescimento no começo dos anos 2000. Assim, para que a produtividade passasse a contribuir para o crescimento brasileiro sustentável no longo prazo, primeiramente, seria necessário que o seu desempenho melhorasse.

Então, seria preciso verificar empiricamente como se comportou a produtividade brasileira para estudar, de maneira mais abrangente, a sua evolução e nível. Contudo, conforme indicou Messa (2014), esta análise esbarra em muitos empecilhos, dada a dificuldade de análise da produtividade desagregada, considerando a falta de dados ou de metodologia para a estimação. Por isto, a maioria das análises teve como enfoque o estudo da produtividade agregada no país, considerando a maior disponibilidade de dados e metodologia de estimação.

Problemas com estimação da produtividade ocorrem ainda mais quando se considera a produtividade do capital brasileira, sendo que poucos trabalhos abordam a metodologia, e quando o abordam focam empiricamente na produtividade agregada brasileira. No Brasil, além de poucas metodologias para o estudo do tema, também há dificuldades a respeito da disponibilidade de dados, sendo que não se conta com uma medida de capital fixo oficial, e o que mais se aproxima para suprir esse gargalo é a série de dados estimada por Morandi e Reis (2004), e que é atualizada periodicamente pelos autores. 
Buscando suprir o gargalo no estudo da produtividade do capital brasileira de forma mais desagregada, este trabalho tem como objetivo principal verificar o desempenho da produtividade e seu impacto para o crescimento econômico. Para isto, o foco é estimar medidas de produtividade desagregadas por setores e regiões, buscando observar comportamentos similares e destoantes entre o desempenho nos diferentes setores e regiões, e a sua influência no crescimento econômico. A medida adotada foi escolhida por causa das diferentes dotações de capital que os setores e as regiões possuem dentro do país, além do gargalo existente na literatura sobre o tema.

Portanto, se pretende contribuir com o estudo empiricamente ao estimar uma medida da produtividade do capital desagregada entre os setores (agropecuária, indústria e serviços) e regiões brasileiras (Norte, Nordeste, Sudeste, Sul e Centro-Oeste) no período de 2002 a 2016, devido à disponibilidade de dados oficiais do IBGE (2020). O intuito da análise é verificar quais regiões e setores foram responsáveis pela maior contribuição para o baixo desempenho agregado. Ademais, também foi procurado verificar o impacto que as taxas de crescimento destas produtividades surtiram no crescimento econômico por meio da decomposição do crescimento, verificando se a tendência de crescimento para ambas as medidas (produção e produtividade) foi a mesma, ou se tiveram comportamentos opostos.

Com esse intuito, o presente trabalho se encontra dividido em quatro seções, além desta introdução e das considerações finais. Na primeira seção é feita uma análise a respeito do comportamento da produção a partir de 1980, período em que passou a decrescer a economia brasileira, tanto em termos de crescimento econômico como em termos de produtividade. $\mathrm{Na}$ segunda seção, um levantamento teórico a respeito do papel da produtividade no crescimento econômico foi realizado, bem como uma breve revisão sobre o comportamento da produtividade no Brasil a partir da segunda metade do século XX. Na terceira seção é apresentada a metodologia utilizada no estudo, bem como a construção das variáveis. E, por fim, na quarta seção são apresentados os resultados e a discussão sobre o comportamento da produtividade do capital assim como da decomposição do crescimento. 


\section{Revisão histórica do crescimento}

A década de 1980 é tida como um período em que o crescimento econômico brasileiro passou a ter queda, sendo que isso decorreu do fato de que o país vinha obtendo crescimento econômico com base no endividamento externo, porém, com a crise econômica que se abateu na América Latina, as opções de financiamento externo foram restritas. Portanto, houve reflexos no PIB brasileiro, cujo crescimento foi negativo nos primeiros anos dessa década, que ficou conhecida como a década perdida. Além da restrição de financiamentos, o país ainda se recuperava dos efeitos dos dois choques do petróleo na década anterior, da alta das taxas de juros americana, com alta inflação. Com o intuito de que o país voltasse a crescer, algumas medidas foram tomadas em 1980, conforme Marangoni (2012), entre elas, a taxa de câmbio no país foi desvalorizada, mas mesmo isto não foi o suficiente para evitar que a balança comercial não tivesse resultado negativo. No ano seguinte, em 1981, o país enfrentou uma recessão. Houve instabilidade tanto monetária quanto cambial no país, e o Fundo Monetário Internacional (FMI) impôs pesadas condições para o país obter empréstimos, algumas dessas medidas acabaram também afetando a capacidade do país de rolar a sua dívida externa.

Já na década de 1990, o crescimento foi superior ao anterior, todavia nos três primeiros anos do período houve queda do PIB, o que pode ser explicado pela alta inflação que assolava o país, além dos resultados do Plano Collor (1990), que foi responsável pelo confisco das poupanças. A partir do ano de 1994 o crescimento passou a apresentar resultado positivo, que entre os fatores responsáveis pode ser citada a maior abertura econômica, mas principalmente, a implantação do Plano Real, em 1995, responsável pela estabilização da economia brasileira. Portanto, o que se pôde concluir da década de 1990 foi que colocou o país de volta no caminho do crescimento econômico com estabilidade. Ademais, houve ligeira queda do PIB entre os anos de 1998 e 1999, o que poderia ter decorrido de resquícios da crise argentina e crise russa no ano de 1998, porém, a partir do ano de 2000 foi reestabelecido o crescimento.

Na década de 2000, o crescimento foi superior ao da década anterior, e, no começo do período, o crescimento do país foi estimulado, segundo De Negri e Cavalcante (2014), principalmente pelo fato de o país ter se beneficiado da variação dos preços relativos. Portanto, o crescimento destes anos decorreu principalmente da alta na produção de bens primários, o que também levou o país a aumentar o 
número de pessoas ocupadas. Contudo, no ano de 2009, como resultado da crise financeira de 2008, houve queda no PIB. Porém, esta redução só ocorreu no ano imediatamente posterior à crise, pois em 2010 a produção voltou a crescer.

Concernente à produtividade, o crescimento que ocorreu por volta os anos 1965 a 1980, de acordo com Menezes-Filho et al. (2014) foi principalmente por causa de melhorias internas nos setores, e, também pelo movimento de deslocamento da mão de obra para os setores mais produtivos da economia. Ademais, afirmaram também que no período abrangendo de 1950 até 1980, a produtividade brasileira cresceu acima da produtividade americana. A produtividade dos serviços e da indústria, segundo os autores, tinham comportamentos similares neste período, porém, foi a indústria que mais influenciou no resultado agregado, e o respectivo crescimento da produtividade. Contudo, devido à queda da produtividade agregada na década de 1980, a agropecuária passou a apresentar maior crescimento embora com queda na mão de obra. Menezes et al. (2014) também afirmaram que foi neste período que a produtividade na indústria iniciou seu comportamento de queda, apesar de ter se recuperado durante o processo de abertura comercial na década de 1990.

Considerando a década de 1980, Silva et al. (2016) afirmaram que as poucas contribuições positivas da produtividade foram principalmente conduzidas por causa da mudança estrutural, ou seja, pelo deslocamento de trabalhadores da agropecuária para os setores da indústria e serviços, concordando com MenezesFilho et al. (2014), que afirmaram que na década houve queda da mão de obra da agropecuária.

Bugarin et al. (2002) afirmaram que durante o período de 1980 até 1998 a produção cresceu. Contudo, os insumos capital e trabalho tiveram crescimentos superiores, o que sugeriu que a produtividade teve comportamento negativo na produção durante o período. Gomes et al. (2003), assim como Bugarin et al. (2002), destacaram o crescimento considerável do estoque de capital fixo por trabalhador na década de 1980, dando mais indícios de que a contribuição da produtividade para o período foi negativa, e que o baixo crescimento da economia se sustentou principalmente no uso de insumos de produção. A queda da produtividade na década de 1980 poderia ainda, de acordo com Ferreira et al. (2008), ter sido causada pelas práticas protecionistas adotadas no país após os dois 
choques do petróleo e a intervenção do Governo nos preços relativos da economia, entre outros.

Menezes-Filho et al. (2014), também afirmaram que a diferença na taxa de crescimento da década de 2000 para 1990 decorreu principalmente dos comportamentos da produtividade e da escolaridade, também entendida como capital humano. Considerando a produtividade, De Negri e Cavalcante (2014) afirmaram que o aumento da taxa de crescimento da década de 2000 em relação a 1990 se deveu ao resultado das reformas na década de 1990, pois, de acordo com o autor, era preciso um longo prazo para que as reformas se refletissem na produtividade.

Já a respeito da produtividade do capital, Bacha e Bonelli (2005), afirmam que durante o período de 1980 até o período dos anos 2000 a sua tendência no Brasil foi de queda, no entanto, afirmam que esta foi uma tendência não somente do país, mas sim observada em vários outros países. Entretanto, eles também concordam que a queda observada no Brasil foi maior do que a observada mundialmente. Os autores afirmam que esta queda na produtividade ocorreu por causa do uso mais intensificado do fator de produção de estoque de capital fixo, e, além disso, também lançaram hipótese de que esta queda poderia ter sido fruto de ineficiências no processo de substituição de importações, da tendência mundial de aumento da intensidade do uso de capital, ou, do ajustamento de longo prazo a uma taxa de poupança mais alta. Também afirmam que foi observada uma correlação negativa entre a produtividade do capital e o preço relativo do investimento. De modo que enquanto houve queda na relação produto-capital, houve aumento no preço relativo dos investimentos, sendo maior do que a média mundial.

O Gráfico 1 apresenta o comportamento da série de produtividade do capital ajustada pelo nível de utilização da capacidade instalada na segunda metade do século XX. É possível verificar que a partir da década de 1970 a produtividade do capital passou a apresentar tendência de queda, de acordo com Bacha e Bonelli (2005), sendo que o único período de leve recuperação foi em meados do início da década de 2000, conforme afirmado por De Negri e Cavalcante (2014). 
$\mathrm{Na}$ década de 1950 a produtividade do capital (PC) ${ }^{1}$ apresentou crescimento, sendo este de 3,41\% a.a. Na década posterior, 1960, a taxa de crescimento da medida caiu, apresentando crescimento médio de 1,03\% a.a. Mesmo com a queda de uma década para a outra, o comportamento da medida seguiu a tendência de crescimento. Já na década de 1970 este quadro se inverteu, a produtividade apresentou queda em 0,24\% a.a. Na década de 1980 também houve queda, em 1,55\% a.a. Esta tendência de queda continuou no período seguinte, sendo que nos anos 1990 teve recuo em 0,76\% a.a., indicando que o período não foi favorável para a produtividade. Já nos anos 2000, esta tendência se modificou um pouco, a produtividade obteve aumento em 0,82\% a.a. Mas, ao contrário do que ocorreu na década de 2000, no período de 2010 a 2014 houve queda, $0,99 \%$ a.a. Contudo, ao considerar todo o período analisado, houve crescimento positivo, sendo de 0,39\% a.a.

\section{Gráfico 1 - Evolução da produtividade do capital brasileira (1950-2014), índice de base fixa $(1950=100)$}

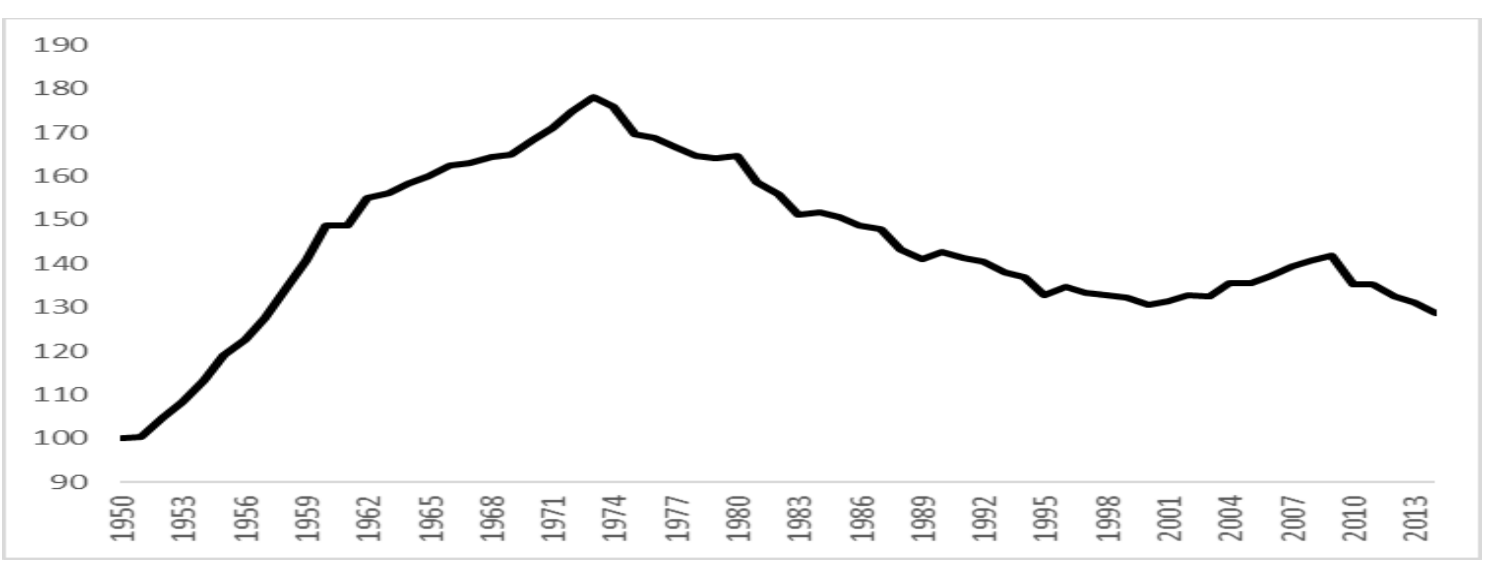

Fonte: elaboração própria com base nos dados da PWT 9.0 e IBRE (2017).

Portanto, ao analisar o padrão histórico na segunda metade do século $\mathrm{XX}$, se confirma que a produtividade do capital passou a apresentar comportamento divergente do crescimento econômico a partir de meados da década de 1970. A próxima seção analisa o papel da produtividade do capital no crescimento por meio da teoria econômica.

\footnotetext{
${ }^{1}$ A metodologia utilizada é de Bacha e Bonelli (2005), os dados de produção e estoque de capital foram retirados da base de dados Penn World Table (PWT, 2017), e os dados de utilização da capacidade instalada foram do IBRE (2017).
} 


\section{Revisão teórica e empírica}

Quando se busca relacionar teoricamente crescimento econômico e produtividade, muito se discute os estudos de três autores, Abramovitz (1956), Kendrick (1956) e Denison (1962), pois foi a partir desses estudos que a produtividade passou a ser considerada primordial para explicar parcela significativa do crescimento, de acordo com Griliches (1998). Conforme apontado pelo autor, Abramovitz, Denison e Kendrick figuravam entre os autores que mais defendiam a produtividade como sendo importante para a determinação do crescimento econômico, porém, como criticou Griliches (1998), estes falharam na explicação teórica da origem da produtividade, ou, também como esta seria medida. Coube a Solow (1956) e Swan (1956) introduzirem a produtividade em um modelo de crescimento econômico, considerando que ambos a chamavam de progresso técnico, ficando assim conhecido como modelo de crescimento econômico Solow-Swan. O modelo de crescimento escolhido partiu da análise de uma função de produção. Para Solow (1956) o progresso técnico era um fator de aumento de escala pelo qual a produção era multiplicada. Enquanto em Swan (1956), o progresso técnico era inicialmente neutro, porém, ia se responsabilizando por aumentos na produção que não eram causados por aumentos do capital ou trabalho, e, também acrescia a produção indiretamente através do seu aumento da contribuição do capital. No entanto, nesse modelo, o progresso técnico era considerado como exógeno ao processo de produção, sendo conhecido então como modelo exógeno.

Em oposição a esses modelos, surgiram os modelos endógenos em que o progresso técnico seria interno ao modelo de crescimento econômico. Dentre estes estudos se encontram Romer (1986), Lucas (1988) e Romer (1990), que foram conhecidos também pela atenção aos rendimentos crescentes à escala e por considerarem modelos em equilíbrio imperfeito, assumindo equilíbrio em competição monopolística, além da inclusão do estoque de capital humano na função de produção. Além desses modelos endógenos, há ainda o modelo de Mankiw et al. (1992) que buscou defender as contribuições de Solow para o crescimento econômico, ao encontrar soluções para algumas das críticas apontadas no seu modelo. Com isto, foi considerado um modelo de Solow aumentado com capital humano, e, para os autores, esta modificação se encaixou melhor na descrição do crescimento dos países, além de buscar responder algumas críticas que o modelo exógeno de Solow recebeu. Ademais, se destaca que apesar de 
receber críticas, o modelo de crescimento de Solow é muito difundido quando se estuda a relação entre crescimento econômico e produtividade.

Abordando de forma mais técnica o tema, na abordagem do modelo SolowSwan, conforme Barro e Sala-i-Martin (2003), parte-se primeiramente de uma função de produção do tipo Cobb-Douglas, em que os fatores de produção são o trabalho e o estoque de capital fixo, além de uma taxa de progresso técnico que é dada de modo exógeno. Neste modelo, os autores concordam que o responsável pelo crescimento seria o estoque de capital e a sua acumulação, porém, os retornos decorrentes deste fator de produção são decrescentes. Portanto, o modelo discorre que os países tendiam a crescer até convergir para o seu estado estacionário. No entanto, o estado estacionário era diferente para cada país, ou seja, não havia convergência de crescimento entre os países, e, também, o estado estacionário poderia mudar, tendendo a aumentar ou baixar dependendo da situação.

No modelo, o valor da produtividade do capital pode estar variando pelo fato de seu valor estar convergindo para um valor estacionário divergente. Para que isso ocorra, a taxa de crescimento estacionário do estoque de capital, $K$ 'ss, seria dada por:

$$
K_{s s}^{\prime}=A^{\prime}+N^{\prime}
$$

Em que $A$ ' se refere à taxa de crescimento da produtividade total dos fatores ampliadora de trabalho. E $N^{\prime}$ se refere à taxa de crescimento da força de trabalho. Sendo que o valor do estado estacionário da produtividade do capital, $v$, é dado por:

$$
v_{s s}=\frac{\delta+A^{\prime}+N^{\prime}}{s\left(\frac{1}{p}\right) \mu}
$$

Onde $v_{s s}$ se refere à produtividade do capital em estado estacionário, $\delta$ é a taxa de depreciação, $s$ é a taxa de poupança, $p$ é o preço relativo do investimento e $u$ é nível de utilização da capacidade instalada. Portanto, conforme já mencionado, o valor do estado estacionário da produtividade do capital também pode variar. Desse modo, a produtividade do capital flutua consideravelmente, tendendo a atingir o novo valor do estado estacionário, sendo que este processo de ajustamento pode ocorrer considerando o longo prazo.

$\mathrm{O}$ estudo da produtividade pode ser feito a partir de algumas metodologias e medidas, tanto da produtividade total dos fatores (PTF), que é uma medida total, 
quanto da produtividade do trabalho (PT) e capital (PC), que são medidas parciais. Barbosa-Filho, Pessôa e Veloso (2010) estudaram o crescimento da produtividade brasileira por meio da PTF entre os anos de 1992 e 2007. No período de 1992 a 1999, a taxa de crescimento foi de 1,4\% a.a., enquanto no período de 1999 a 2007 foi de 0,11\% a.a. Na estimação, o estudo fez uso do nível de utilização da capacidade instalada e capital humano inclusos na função de produção.

Bonelli e Veloso (2012) estudaram crescimento da PTF no Brasil no período de 1995 a 2009, concluindo que durante o período de 1995 a 2003 o crescimento médio da PTF foi negativo em 0,8\% a.a., enquanto no período de 2003 a 2009 foi positivo em 1,7\% a.a. A estimação foi feita a partir de uma função do tipo Cobb-Douglas acrescida do nível de utilização da capacidade instalada. É possível verificar que os resultados encontrados divergem dos resultados de Barbosa-Filho, Pessôa e Veloso (2010).

Assim como Bonelli e Veloso (2012), Bonelli e Bacha (2013) utilizaram a mesma metodologia, porém, com foco no período de 1990 a 2011. O estudo concluiu que nos três primeiros anos do estudo a produtividade se manteve praticamente inalterada. No período de 1993 a 1999, afirmaram que a taxa média de crescimento da PTF foi de 0,24\% a.a., enquanto no período de 2000 a 2011 o crescimento foi de $1,03 \%$ a.a.

Adotando uma metodologia um pouco diferenciada, Ferreira e Veloso (2013) estimaram a PTF fazendo uso do capital humano na função de produção e utilizando dados em dólares em paridade do poder de compra. Ao analisar o período de 1993 a 2003 indicaram um decréscimo da produtividade em 1,2\%, enquanto no período de 2003 a 2009 o crescimento foi positivo em 1,5\%. Bonelli (2014), ao estudar o crescimento da produtividade total dos fatores brasileiras no período de 2003 a 2013, encontrou que o crescimento médio foi de 1,3\% a.a., valor próximo ao obtido por Bonelli e Veloso (2012).

Ao abordar a produtividade do capital mais especificamente no caso brasileiro, diversos estudos concordaram a respeito do comportamento da produtividade do capital brasileira na segunda metade do século XX, entre eles Bonelli e Fonseca (1998). Os autores afirmaram que por causa de uma aceleração no estoque de capital também houve queda da produtividade do capital no período de 1970 a 1978, período em que não houve queda no crescimento econômico, diferentemente da década de 1980. Bacha e Bonelli (2005) também afirmaram que 
na década de 1970 houve queda na produtividade do capital e que isto ocorreu porque processos de produção mais intensivos em capital foram adotados no mundo inteiro por causa da Crise do Petróleo, porém, que no Brasil isto também decorreu de aumento no preço relativo dos bens de investimento. Além disso, também apontaram a baixa da produtividade do capital como resultado da ineficiência do processo de substituição de importações e o ajustamento de longo prazo a uma taxa de poupança mais alta.

Duménil e Lévy (2007) afirmaram que, de 1948 a 1984, houve tendência de declínio na produtividade do capital, ou produtividade por unidade de capital fixo, e que após este período, até o ano de 2005, houve retomada da tendência de crescimento; diferentemente de Bonelli e Fonseca (1998), que afirmaram que a produtividade do capital diminuiu em média $10 \%$ na década de 1980 e que isto ocorreu por causa do elevado grau de estoque de capital utilizado. Esta queda também coincidiu com a desaceleração do crescimento econômico. Marquetti (2002), assim como Duménil e Lévy (2007) concordou que houve declínio no período da década de 1980. Para ele, a produtividade do capital sofreu forte declínio na segunda fase (1975-1991) do progresso técnico, e que na primeira fase (1955-1975) houve pouca queda, e na terceira fase (1991-1998) houve relativa estabilidade. O autor afirmou que de 1955 a 1998 a produtividade do capital declinou em $62,6 \%$.

Já Morandi e Reis (2004) estudaram a produtividade no período de 1950 a 2002, e afirmaram que houve aumento na produtividade nos períodos de 1970 a 1981, 1986-1987, e redução na década de 1950, e 1983 a 1984, 1990 a 1994 e 1998 a 2002. Afirmaram também que investimentos realizados em máquinas e equipamentos não apenas melhoraram sua vida útil como também melhoraram sua produtividade. Por fim, Gasques et al. (2008) estudaram a produtividade do capital na agricultura e afirmaram que no período de 1975 a 2007, a produtividade do capital aumentou cerca de $169,74 \%$. Sendo que no período de 2000 a 2007 a taxa de crescimento foi mais acentuada, sendo $4,88 \%$.

Assim, a importância da produtividade do capital para o crescimento econômico de longo prazo pode ser explicada pela abordagem ao modelo de Solow-Swan e demonstra o quanto o processo de acumulação de capital fixo é importante neste sentido. Em termos empíricos no Brasil, se conclui que há certo consenso de que a produtividade do capital passou a apresentar comportamento de 
declínio a partir da década de 1970 no país. Tendo em vista as evidências apresentadas, a próxima seção apresenta os procedimentos metodológicos que foram utilizados para poder analisar como foi o desempenho da produtividade do capital nos setores e regiões brasileiras.

\section{Metodologia}

\subsection{Base de dados}

O valor bruto da produção por atividade e região e o índice de preços forneceram a estimativa de produção real e foram obtidos do IBGE (2020). Já a população foi utilizada para o cálculo da taxa de crescimento populacional; a produção, deflator implícito e horas trabalhadas dos Estados Unidos ${ }^{2}$ foram necessárias para estimação da taxa de progresso técnico ou fronteira de progresso tecnológico. O investimento, depreciação e capital líquido residencial e o não residencial dos Estados Unidos $^{3}$ foram usados no cálculo da taxa de depreciação, e foram obtidos do BEA (2017). Essas taxas, conjuntamente com a formação bruta de capital fixo, deflator implícito, produção regional e produção nacional, obtidos do IBGE (2020), foram fundamentais para a metodologia de cálculo do estoque de capital fixo, com a produção nacional sendo utilizada para o cálculo do produto potencial, e, consequentemente, o nível de utilização da capacidade instalada. Para a mensuração da população ocupada foram utilizados os microdados da PNAD (2020), considerando as unidades de federação, grupamento de atividades no trabalho, idade do morador, situação de ocupação e peso da pessoa na amostra.

\subsection{Métodos}

O cálculo da produtividade possui problemas de mensuração como afirmado por Messa (2014) e De Negri e Cavalcante (2014). Os autores mostraram que a dificuldade reside na decisão de qual medida de produção usar, se produção total ou valor adicionado, se a medida usada seria de produção física ou por indicador monetário, visto que este último poderia mostrar variações que não seriam de eficiência, além de também ser necessário decidir sobre o uso do nível de utilização

\footnotetext{
${ }^{2}$ A taxa de crescimento da produtividade do trabalho nos Estados Unidos foi considerada como fronteira tecnológica para Gomes et al. (2003). Sendo que, ela foi definida como o maior nível possível de ser alcançado em uma trajetória.

${ }^{3}$ A taxa de depreciação foi calculada com base nas Contas Nacionais dos EUA por causa da confiabilidade dos seus dados, conforme Gomes et al. (2003).
} 
da capacidade instalada. Por sua vez, há a difícil mensuração do estoque de capital, que na maioria das vezes foi estimado pelo método do inventário perpétuo, como dito por De Negri e Cavalcante (2014) e Ellery Junior (2014).

O intuito do trabalho é calcular a produtividade do capital brasileira e analisar o seu desempenho no período de 2002 até 2016. Se buscou mensurar a produtividade do capital para contribuir empiricamente com os estudos focados no Brasil, considerando que na literatura existente há maior destaque para estudos que abrangem a produtividade do trabalho ou produtividade total dos fatores. Ademais, a contribuição do estudo ocorre por meio da mensuração da produtividade do capital tanto em termos setoriais quanto regionais. O período analisado foi escolhido devido às restrições dos bancos de dados das Contas Regionais do IBGE, sendo que há mudanças de metodologia antes de 2002 e os dados mais recentes em termos regionais são do ano de 2016.

A desagregação foi feita considerando os três macrossetores da economia, agropecuária, indústria e serviços, além de também ser estimado o agregado. Também foi realizada a desagregação por grandes regiões, Norte, Nordeste, Sudeste, Sul e Centro-Oeste, além, é claro, da estimação considerando o Brasil no agregado. Este trabalho procurou seguir algumas sugestões de Ellery Jr. (2014) para a metodologia utilizada na estimação da produtividade do capital. Sendo, portanto, considerada em sua estimação, além dos fatores tradicionais (produto e capital), o nível de utilização da capacidade instalada.

Foi necessário decidir sobre a unidade de medida que seria considerada para indicar a produção agregada. E, de acordo com Ellery Junior (2014), como a produtividade foi calculada por grande região e macrossetor, sendo medidas mais desagregadas, foi preferível usar o valor bruto da produção, de modo a impedir viés na estimação. A produção real foi obtida utilizando o índice de preços das Contas Regionais, sendo o valor da produção do macrossetor dado pela soma das atividades pertencentes a ele. Em seguida foi construído o estoque de capital fixo, utilizando a metodologia do inventário perpétuo, em que:

$$
K_{t+1}=(1-\delta) K_{t}+I_{t}
$$

Sendo $K_{t+1}$ e $K_{t}$ o estoque de capital agregado no período $t+1$ e $t, I_{t}$ o investimento anual bruto e $\delta$ a taxa de depreciação do estoque de capital fixo anual. Para estimar a série foi necessário um valor inicial do estoque de capital fixo e a 
taxa de depreciação. Seguindo Gomes et al. (2003), o estoque inicial foi obtido por:

$$
K_{0}=\frac{I_{0}}{(1+g)(1+n)-(1-\delta)}
$$

Com $K_{0}$ sendo o estoque de capital inicial, $I_{0}$ o investimento inicial, $g$ a taxa de progresso técnico anual e $n$ a taxa de crescimento populacional anual. De acordo com Gomes et al. (2003), o investimento inicial foi obtido pela média do investimento dos cinco primeiros anos do período. Todos os dados foram deflacionados pelo índice de preços das Contas Regionais e as atividades foram agregadas de acordo com os respectivos macrossetores a que pertenciam. A taxa de progresso técnico foi considerada como a taxa de crescimento anual da produtividade do trabalho dos Estados Unidos ${ }^{4}$. E a depreciação foi calculada seguindo a equação:

$$
\delta=1-\frac{K_{t+1}-I_{t}}{K_{t}}
$$

A depreciação utilizada foi calculada considerando dados dos Estados Unidos, conforme sugerido por Gomes et al. (2003), dada a confiabilidade dos dados. Após a estimação do estoque de capital fixo nacional, foi possível utilizar a metodologia de Garofalo e Yamarik (2002) para estimar os estoques das grandes regiões:

$$
k_{t, i, j}=\left[\frac{y_{t, i, j}}{Y_{t, i}}\right] K_{t, i, j}
$$

Com $k_{t, i, j}$ sendo o estoque de capital fixo por grande região e $y_{t, i, j}$ o produto por grande região. Enquanto $Y_{t, i}$ e $K_{t, i, j}$ são a produção e o estoque de capital fixo nacionais, respectivamente. O cálculo do nível de utilização da capacidade instalada foi realizado se baseando em Feijó (2006):

$$
u_{t, i, j}=\frac{Y_{t, i, j}}{Y^{*}{ }_{t, i, j}}
$$

\footnotetext{
${ }^{4}$ Considerada como a fronteira tecnológica para PTF de acordo com Gomes et al. (2003).
} 
Em que $u_{t, i, j}$ é o nível de utilização da capacidade instalada, $Y_{t, i, j}$ é a produção efetiva agregada e $Y_{t, i, j}^{*}$ é a produção potencial. O produto potencial foi obtido através do uso do filtro de Hodrick Prescott ${ }^{5}$, conforme sugerido por Sala (2014). A produtividade do capital foi estimada através da razão entre a produção $(Y)$ e o estoque de capital fixo ajustado pelo nível de utilização da capacidade instalada $(u K)$, conforme sugerido por Bonelli (2014):

$$
v=\frac{Y_{t, i, j}}{u K_{t, i, j}}
$$

Além disso, também foi realizada a decomposição do crescimento pela metodologia de Bacha e Bonelli (2005), sendo derivada de um modelo $Y=A K$.

$$
\frac{1}{N} \ln \left(\frac{Y_{t+N}}{Y_{t}}\right)=\frac{1}{N} \ln \left(\frac{v_{t+N}}{v_{t}}\right)+\frac{1}{N} \ln \left(\frac{u_{t+N}}{u_{t}}\right)+\frac{1}{N} \ln \left(\frac{K_{t+N}}{K_{t}}\right)
$$

A partir dela foi possível verificar qual o impacto da produtividade do capital no crescimento econômico. Bem como também mensurar a contribuição do estoque de capital fixo. Além disso, também foi realizada outra decomposição do crescimento sugerida por Bacha e Bonelli (2005), derivada do modelo Solow-Swan:

$$
\frac{1}{N} \ln \left(\frac{Y_{t+N}}{Y_{t}}\right)=\frac{1}{N} \ln \left(\frac{1}{\frac{v_{t+N}}{v_{t}}}\right)+\frac{1}{N} \ln \left(\frac{A_{t+N}}{A_{t}}\right)+\frac{1}{N} \ln \left(\frac{L_{t+N}}{L_{t}}\right)
$$

Em que $A$ se refere ao progresso técnico ampliador de trabalho, ou produtividade total dos fatores, $L$ se refere ao emprego e $1 / v$ se refere ao aprofundamento do capital (diferença do crescimento do estoque de capital em uso e o crescimento do trabalho efetivo).

A metodologia de cálculo utilizada para o cálculo de A foi obtida de Barbosa-Filho e Pessôa (2014):

$$
A_{t}=\frac{Y_{t}}{\left(u_{t} K_{t}\right)^{\alpha} L_{t}^{1-\alpha}}
$$

O parâmetro $\alpha$ utilizado foi de 0,40 , conforme sugerido por Souza e Cunha (2018). A próxima seção apresenta os resultados obtidos e a sua discussão.

\footnotetext{
${ }^{5} \mathrm{O}$ filtro foi feito utilizando o software econométrico Eviews.
} 


\section{Resultados e discussões}

Para a estimação do estoque de capital fixo, os valores da taxa de progresso técnico, taxa de crescimento populacional e taxa de depreciação obtidos foram, $0,94 \%$ a.a., $1,03 \%$ a.a. e 3,65\% a.a., respectivamente. Novamente, os resultados foram estimados utilizando dados que representassem a realidade do período analisado, 2004 a 2016. Já a produtividade do capital está apresentada na Figura 1a, sendo verificado que do ano de 2008 a 2009 a produtividade do capital decresceu, o que indicou que a partir da crise financeira o investimento em formação bruta do capital fixo foi menor, levando ao menor estoque de capital fixo, além de outros fatores. De 2010 a 2011 a produtividade do capital teve ligeiro crescimento, no entanto, a partir de 2011 até o final do período passou a decrescer. Apesar desse período de estagnação no fim, o crescimento observado no início do período influenciou na variação percentual média do período que foi de 9,35\% a.a.

A produtividade do capital setorial está exibida na Figura $1 \mathrm{~b}$ e se nota que os três setores começaram o período com tendência de crescimento, no entanto, todos os setores tiveram desaceleração durante a crise de 2008, voltando a crescer a partir de 2010. O que se nota é que somente a agropecuária seguiu trajetória de crescimento durante todo o período, sendo que a indústria e os serviços passaram a apresentar comportamento de estagnação assim ocorreu quando se considerou o agregado da economia. Apesar do comportamento declinante a partir da metade no período tanto na indústria quanto nos serviços, a variação percentual do crescimento da produtividade do capital média foi positiva no período, $13,81 \%$ a.a. para agropecuária, $6,42 \%$ a.a. para indústria e $12,35 \%$ a.a. para os serviços. Portanto, se verifica que na indústria e serviços (setores responsáveis por maior parcela do PIB), a produtividade do capital se manteve praticamente inalterada de 2011 até 2016.

Com relação à evolução da produtividade do capital por região se destaca a tendência de queda após o ano de 2008, com leve recuperação até o período de 2011 e seguida de estagnação ou queda em todas as regiões. Apesar do comportamento de estagnação a partir de 2011, assim como ocorreu quando se considerou o agregado e os setores, a variação percentual de crescimento da produtividade foi positiva em todas as regiões. A região Nordeste teve maior variação percentual de crescimento no período $10,22 \%$ a.a., seguida pelo CentroOeste e Norte, $9,86 \%$ a.a. e 9,82\% a.a., respectivamente. A região com menor 
variação percentual no período (mas ainda considerável) foi o Sul, 8,78\% a.a. Portanto, é possível verificar que o comportamento da trajetória da produtividade do capital é similar para todas as regiões, e um reflexo desse comportamento é observado quando se considera o agregado brasileiro.

Conforme mencionado anteriormente, o setor de agropecuária foi o único a apresentar trajetória positiva durante todo o período analisado. A Figura 1d apresenta o comportamento da agropecuária para todas as regiões, e se verifica que todas apresentam comportamento positivo da produtividade em todo o período, assim como a agropecuária nacional. Assim, a maior variação percentual média positiva no período foi observada na região Norte, 18,76\% a.a. A segunda região a apresentar maior variação percentual no período foi o Nordeste,14,83\% a.a., seguida pela região Centro-Oeste, 13,94\% a.a., e Sudeste, 13,26\% a.a. A região com menor variação percentual foi o Sul, 12,91\% a.a. Vale destacar que as regiões Norte, Nordeste e Centro-Oeste obtiveram variação percentual superior à média nacional, $18,81 \%$ a.a.

Quando se considera o setor industrial, Figura 1e, todas as regiões apresentam comportamento similar ao obtido quando considerada a média nacional, não houve disparidades de comportamento setorial entre as regiões. $\mathrm{O}$ que se observa é que houve crescimento da produtividade do capital na indústria até o ano de 2008, seguida de queda e ligeiro crescimento, seguida de longo decréscimo novamente até o final do período. Apesar da trajetória de queda após 2011, a variação percentual média foi positiva para o período. Sendo que a região que obteve maior variação foi o Centro-Oeste, 7,57\% a.a., seguida pelo Nordeste, 7,05\% a.a., Norte, 6,94\% a.a., Sudeste, 6,36\% a.a., e Sul, 6,06\% a.a. Se destaca que somente as regiões Centro-Oeste, Nordeste e Norte obtiveram variação média acima da nacional, $6,42 \%$ a.a. 
Figura 1 - Índices de Produtividade no Brasil, Setorial e Regional (2002-2016)

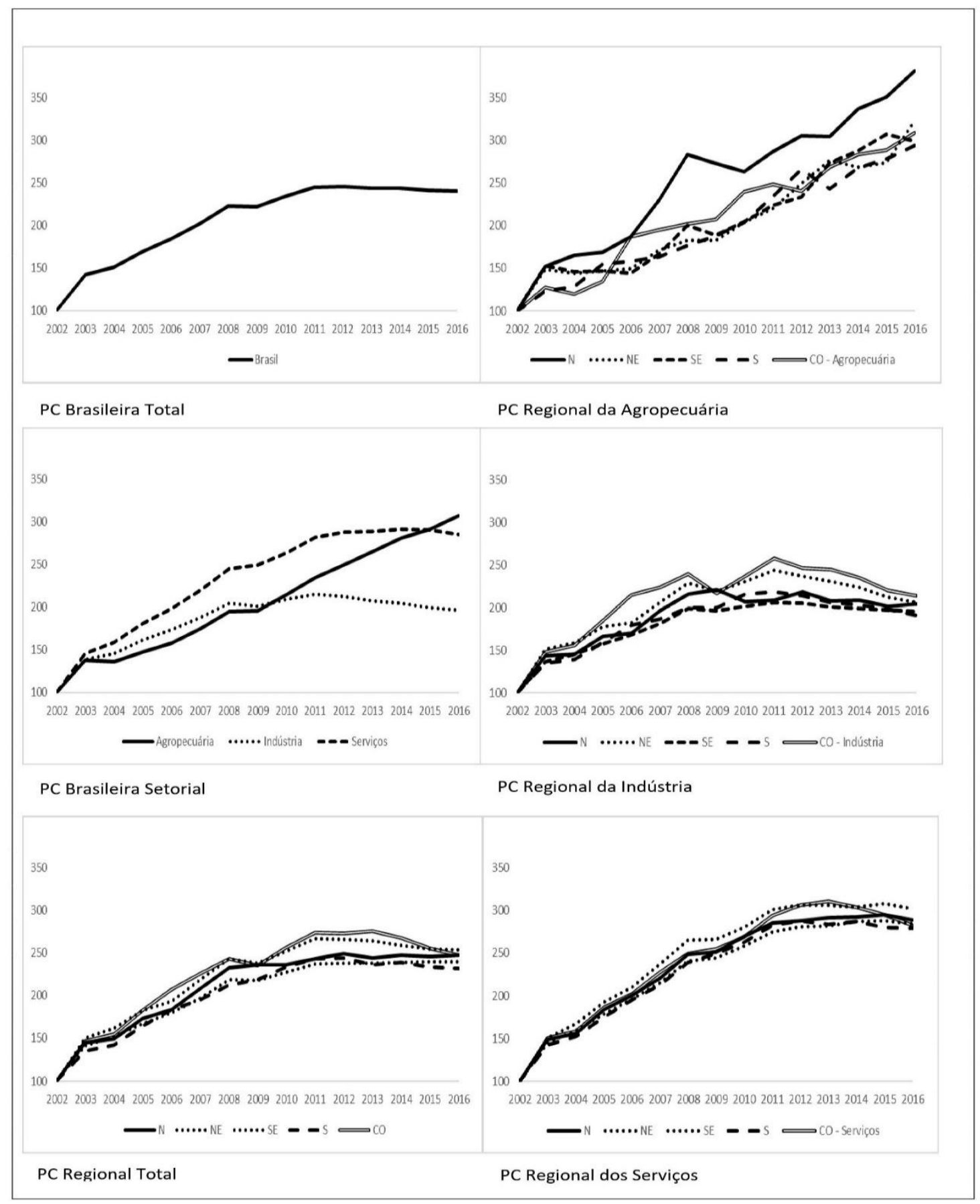

Fonte: elaboração própria com dados do IBGE, BCB, BEA e PNAD (2020).

$\mathrm{N}=$ Norte, $\mathrm{NE}=$ Nordeste, $\mathrm{SE}=$ Sudeste, $\mathrm{S}=\mathrm{Sul}$ e $\mathrm{CO}=$ Centro-Oeste .

Bem como no agregado, a produtividade do capital nos serviços por região, reproduzida na Figura 1f, teve tendência de crescimento até o ano de 2011, com ligeiro decréscimo pós crise de 2008. No entanto, a partir do ano de 2011, a trajetória da produtividade do capital se manteve em patamar semelhante em todas 
as regiões. Apesar desse comportamento no final do período, a variação percentual média do período foi positiva para todas as regiões, sendo superior no Nordeste, $13,46 \%$ a.a., seguido pelo Norte, $12,57 \%$ a.a., Sudeste, $12,27 \%$ a.a., Centro-Oeste, $12,19 \%$ a.a. e Sul, 11, $93 \%$ a.a. As regiões Nordeste e Norte, obtiveram variação superior à média nacional, 12,35\% a.a. Quando se comparam todas as regiões e setores, se observa que a variação percentual da agropecuária foi muito superior à dos outros setores em todas as regiões. Também se destaca que as regiões Norte e Nordeste possuem desempenho acima da média nacional em todos os setores. Além disso, também se observa que a região Sul possui desempenho inferior ao das demais regiões em todos os setores, em termos de produtividade do capital. Por último, se observa que todas as regiões seguiram trajetória semelhante ao da média nacional.

Ao verificar a decomposição do crescimento para analisar o papel da produtividade do capital na produção, foram obtidos os resultados da Tabela 1. Considerando o agregado, o maior crescimento da produção foi no Centro-Oeste, $10,39 \%$ a.a., sendo que houve crescimento na produção em todas as regiões. Ao se considerar a produtividade do capital (v), também se verifica que houve crescimento em todas as regiões, sendo que o crescimento superior foi na região Nordeste, 6,20\%, enquanto o menor crescimento foi observado na região Sul, $5,61 \%$. Em seguida, se verificou que em termos de capacidade instalada houve queda em todas as regiões. Analisando o estoque de capital fixo, novamente se verifica crescimento em todas as regiões durante o período, com maior crescimento no Centro-Oeste e menor crescimento no Sudeste. Portanto, no agregado, se verifica que a produtividade do capital foi o fator que mais contribuiu para o crescimento da produção. 
Tabela 1 - Decomposição do Crescimento por Macrossetor e

Grande Região (2002-2016) (a.a.)

\begin{tabular}{lcccc}
\hline \multicolumn{1}{c}{ Setor/Região } & $\mathbf{Y}$ & $\mathbf{v}$ & $\mathbf{u}$ & $\mathbf{K}$ \\
\hline Total & & & & \\
Brasil & 8.76 & 5.85 & -1.13 & 4.05 \\
Norte & 9.65 & 6.04 & -1.33 & 4.93 \\
Nordeste & 9.29 & 6.20 & -1.48 & 4.57 \\
Sudeste & 8.25 & 5.83 & -1.11 & 3.54 \\
Sul & 8.91 & 5.61 & -0.89 & 4.19 \\
Centro-Oeste & 10.39 & 6.05 & -1.34 & 5.67 \\
\hline Agropecuária & & & & \\
Brasil & 9.03 & 7.48 & -0.19 & 1.74 \\
Norte & 10.72 & 8.93 & -1.64 & 3.43 \\
Nordeste & 7.44 & 7.81 & -0.52 & 0.15 \\
Sudeste & 8.47 & 7.30 & -0.01 & 1.18 \\
Sul & 8.69 & 7.18 & 0.11 & 1.40 \\
Centro-Oeste & 10.80 & 7.53 & -0.24 & 3.51 \\
\hline Indústria & & & & \\
Brasil & 7.79 & 4.50 & -0.82 & 4.12 \\
Norte & 8.73 & 4.76 & -1.08 & 5.06 \\
Nordeste & 8.28 & 4.81 & -1.14 & 4.61 \\
Sudeste & 7.18 & 4.47 & -0.79 & 3.51 \\
Sul & 8.15 & 4.31 & -0.64 & 4.47 \\
Centro-Oeste & 10.66 & 5.06 & -1.39 & 6.98 \\
\hline Serviços & & & & \\
Brasil & 9.45 & 6.99 & -1.58 & 4.04 \\
Norte & 10.31 & 7.07 & -1.66 & 4.90 \\
Nordeste & 10.17 & 7.37 & -1.96 & 4.76 \\
Sudeste & 9.02 & 6.96 & -1.55 & 3.61 \\
Sul & 9.66 & 6.84 & -1.43 & 4.25 \\
Centro-Oeste & 10.20 & 6.93 & -1.52 & 4.79 \\
\hline
\end{tabular}

Fonte: elaboração própria com base nos dados do IBGE, PNAD, BCB e BEA (2020).

A respeito do setor agropecuário, houve crescimento em todas as regiões em termos de produção, sendo o maior crescimento observado no Centro-Oeste, assim como ocorreu com o agregado. Em termos da produtividade do capital também foi observado crescimento em todas as regiões. O maior crescimento da produtividade do capital na agropecuária ocorreu no Norte e o menor no Sul. Relacionado ao nível de utilização de capacidade instalada, se observou queda em todas as regiões, com exceção do Sul em que houve ligeiro crescimento. Sobre o estoque de capital fixo, existiu crescimento em todas as regiões, porém, não foi um crescimento tão homogêneo. A região com maior crescimento foi o Centro-Oeste e a região com o menor crescimento foi o Nordeste, respectivamente as regiões 
com características de pecuária extensiva e agricultura familiar. Ademais, o crescimento da produtividade do capital foi muito superior ao crescimento do estoque de capital fixo.

Em relação à indústria, como observado na Tabela 1, nota-se crescimento positivo para todas as regiões, com destaque para o Centro-Oeste como o local onde houve maior crescimento, $10,66 \%$ a.a. Novamente, houve crescimento na produtividade do capital em todas as regiões durante o período, o maior crescimento também foi observado no Centro-Oeste, 5,06\% a.a. A respeito do nível de utilização da capacidade instalada, foi constatada queda em todas as regiões. Já relacionado ao estoque de capital fixo, houve crescimento em todas as regiões, com destaque para o Centro-Oeste novamente. Ao comparar as contribuições dos fatores, no setor industrial, se observa que o crescimento da produtividade do capital é inferior ao crescimento do estoque de capital fixo para o Norte, Sul e Centro-Oeste.

A respeito dos serviços, houve maior taxa de crescimento da produção no Norte, Nordeste e Centro-Oeste, taxas muito similares, nesse setor também houve crescimento positivo da produtividade do capital. Neste caso, o Nordeste foi a região em que houve maior crescimento, 7,37\% a.a. A taxa de crescimento da utilização de capacidade instalada foi negativa, assim como ocorreu na grande maioria dos setores e regiões. A respeito do estoque de capital fixo, houvesse verificou crescimento em todas as regiões, com o maior crescimento observado no Norte e o menor no Sudeste. Portanto, se pode concluir que houve crescimento no período para todos os setores e regiões em termos de produção, produtividade do capital e estoque de capital fixo. Também se observou que o crescimento da produtividade do capital foi superior ao crescimento do estoque de capital fixo, à exceção de algumas regiões quando considerado o setor de indústria.

A Tabela 2 apresenta a decomposição do crescimento derivada do modelo Solow-Swan. Primeiramente, ao analisar o agregado da economia, se verifica como anteriormente mencionado, que o crescimento do PIB em todas as regiões foi positivo. No entanto, ao analisar a relação $1 / v$, se constata que o crescimento foi negativo no período, mas, ao analisar $v$ anteriormente se constatou crescimento, lembrando que o aprofundamento do capital é a razão entre estoque de capital e uso intensivo de trabalho, ou seja, o crescimento do trabalho foi superior ao estoque de capital. Ademais, ao se estudar nessa decomposição a parcela de 
contribuição de $A$, se verifica que a contribuição foi positiva no período. $\mathrm{O}$ crescimento também foi observado com relação à variável trabalho $(L)$, com exceção das regiões Nordeste e Sul.

Tabela 2 - Decomposição do Crescimento por Macrossetor e Grande Região (2002-2016) (a.a.)

\begin{tabular}{lcccc}
\hline \multicolumn{1}{c}{ Setor/Região } & $\mathbf{Y}$ & $\mathbf{1 / v}$ & $\mathbf{A}$ & $\mathbf{L}$ \\
\hline Total & & & & \\
Brasil & 8.71 & -3.89 & 6.73 & 0.09 \\
Norte & 9.26 & -4.11 & 6.85 & 0.59 \\
Nordeste & 9.59 & -3.79 & 7.55 & -0.46 \\
Sudeste & 8.32 & -3.79 & 6.33 & 0.29 \\
Sul & 8.47 & -4.12 & 6.82 & -0.16 \\
Centro-Oeste & 9.97 & -4.19 & 7.09 & 0.95 \\
\hline Agropecuária & & & & \\
Brasil & 7.62 & -6.35 & 8.90 & -2.98 \\
Norte & 10.50 & -6.28 & 9.75 & -1.56 \\
Nordeste & 7.34 & -5.35 & 8.71 & -3.62 \\
Sudeste & 6.90 & -6.21 & 7.73 & -1.84 \\
Sul & 7.09 & -6.44 & 9.34 & -4.18 \\
Centro-Oeste & 8.38 & -7.36 & 9.15 & -1.96 \\
\hline Indústria & & & & \\
Brasil & 7.29 & -2.59 & 5.09 & 0.53 \\
Norte & 8.07 & -2.71 & 5.20 & 1.20 \\
Nordeste & 8.32 & -2.40 & 5.26 & 1.15 \\
Sudeste & 6.76 & -2.52 & 5.09 & -0.04 \\
Sul & 7.22 & -2.90 & 5.07 & 0.70 \\
Centro-Oeste & 9.76 & -2.85 & 6.03 & 1.61 \\
\hline Serviços & & & & \\
Brasil & 9.96 & -5.02 & 7.45 & 0.90 \\
Norte & 10.28 & -5.32 & 7.43 & 1.44 \\
Nordeste & 10.77 & -5.07 & 7.95 & 0.90 \\
Sudeste & 9.65 & -4.95 & 7.32 & 0.75 \\
Sul & 10.01 & -5.09 & 7.56 & 0.80 \\
Centro-Oeste & 10.42 & -5.17 & 7.46 & 1.43 \\
\hline
\end{tabular}

Fonte: elaboração própria com base nos dados do IBGE, PNAD, BCB e BEA (2020).

Ao se observar o setor agropecuário, assim como ocorreu com o agregado da economia, o crescimento foi positivo tanto na produção, quanto em $A$. Já os fatores aprofundamento do capital $(1 / v)$ e trabalho $(L)$ tiveram queda no período, isso está de acordo com o observado empiricamente para o Brasil, onde se verifica migração de trabalho da agropecuária para os setores de indústria e serviços; assim, o setor primário tem se tornado mais mecanizado, conforme observado por Squeff 
e De Negri (2014). Na indústria, setor secundário da economia, é perceptível crescimento em todas as regiões para a produção, e isso também é observado para $A$ e $K$, com exceção da região Sudeste. A respeito do aprofundamento do capital, houve queda em todas as regiões no período. Por fim, ao se analisar o setor de serviços, se verifica que a relação $1 / v$ é negativa no período, enquanto $A$ e o trabalho são positivos.

Desse modo, o que se verificou considerando ambas as decomposições foi um cenário positivo em termos produção, produtividade do capital e produtividade total dos fatores. A respeito do estoque de capital, também houve crescimento, e, sobre o trabalho, com exceção da agropecuária também há crescimento. Essa queda do número de postos de trabalho na agropecuária está de acordo com o defendido por Bonelli (2014) e Squeff e De Negri (2014), indicando que há forças migratórias do setor em direção à indústria e os serviços.

Portanto, verificou-se que houve crescimento na produtividade do capital em todos os setores e regiões (apesar da estagnação após 2011), e, também, foi o fator que mais contribuiu positivamente para o crescimento da produção. Portanto, se verifica a importância de um bom desempenho da produtividade do capital para o crescimento econômico. Ademais, ao comparar o desempenho de todas as regiões dentro dos setores específicos, se percebe que não há comportamentos díspares entre as regiões, sendo que seguem uma trajetória de comportamento similar. E que esse comportamento é bem expresso pela trajetória da produtividade do capital nacional de cada setor.

Sobre as diferenças entre os setores, se percebe que a produtividade do capital na agropecuária teve trajetória de crescimento durante todo o período, sendo pouco afetada pela crise de 2008. Esses resultados estão de acordo com os resultados de Gasques et al. (2008), conforme comentado anteriormente. Já nos setores de indústria, serviços e no agregado, o que se verificou foi uma taxa de crescimento no período positiva, no entanto, com estagnação a partir do ano de 2011. Ademais, a respeito das regiões, se destacou o Norte e Nordeste como regiões com excelente desempenho a respeito do crescimento da produção e da produtividade do capital, independente do setor analisado. Já o Sul teve desempenho inferior ao das demais regiões em todos os setores, apesar de contar com crescimento no período. 
Desse modo, ao levar em consideração os últimos anos do período, mais especificamente a partir de 2011, se verificou estagnação na trajetória da produtividade do capital, o que está de acordo com o defendido por Bonelli e Fonseca (1998), Bacha e Bonelli (2005), Duménil e Lévy (2007) e Marquetti (2002), conforme observado na seção de revisão de literatura, necessitando que haja inversão neste cenário a fim de obter crescimento econômico sustentável no longo prazo.

\section{Considerações finais}

Em relação à teoria que liga a produtividade ao crescimento econômico, o que pôde ser observado foi que há preocupação com esta relação, sendo considerada como uma das peças-chave para estimular crescimento econômico de longo prazo. A respeito da produtividade brasileira, se verificou certa concordância em relação ao seu desempenho nos últimos anos estar baixo, porém, também ter sido baixo em vários momentos desde a década de 1950. Ao considerar a produtividade do capital, o que se verificou foi a sua tendência contínua de estagnação e queda após o ano de 2011, sendo que, somente o setor de agropecuária seguiu trajetória de crescimento após esse período. Assim, considerando a decomposição do crescimento por meio da produtividade do capital, o que se verificou foi que todos os fatores contribuíram positivamente para o crescimento da produção, à exceção do nível de utilização da capacidade instalada, e que desses fatores, o que mais contribuiu foi a produtividade do capital, à exceção de algumas regiões no setor industrial. Portanto, considerando os resultados das estimações da produtividade, foi verificada a existência de heterogeneidade setorial no país, em que a agropecuária segue tendência ascendente em todas as regiões, enquanto indústria e serviços permaneceram estagnados.

Portanto, se o intuito é que a produtividade passe a apresentar desempenho melhor, seria preciso estimular a produtividade tanto na indústria quanto nos serviços, por estarem apresentando estagnação e serem os setores responsáveis pela maior parcela da composição do PIB. Ou seja, a produtividade do capital nos últimos anos apresentou crescimento insatisfatório, não contribuindo para o crescimento econômico das regiões e do país. Portanto, é necessário estimular o aumento da eficiência do estoque de capital fixo no processo de produção brasileiro, de modo que passe a apresentar resultados positivos. Desse modo, é preciso que haja maior investimento produtivo no país para que haja melhoria de eficiência ao invés de maior investimento especulativo. Também, considerando a 
diferente dotação de capital dos setores, se verificou que houve impacto no desempenho da produtividade do capital, como no caso da indústria (setor que possui maior nível de estoque de capital fixo), que apresentou menor eficiência dentre os setores considerados. Assim, é verificada a existência de heterogeneidade setorial em relação à produtividade do capital.

\section{Referências}

ABRAMOVITZ, M. Resource and output trends in the United States since 1870. American Economic Growth, v. 46, n. 2, p. 5-23, 1956.

BACHA, E.; BONELLI, R. Uma interpretação das causas da desaceleração econômica no Brasil. Revista de Economia Política, v. 25, n. 3, p. 163-189, 2005.

BARBOSA-FILHO, F.; PESSÔA, S. Pessoal ocupado e jornada de trabalho: uma releitura da evolução da produtividade no Brasil. Revista Brasileira de Economia, v. 68 , n. 2, p. 149-169, 2014.

BARBOSA-FILHO, F.; PESSÔA, S.; VELOSO, F. Evolução da produtividade total dos fatores na economia brasileira com ênfase no capital humano - 1992-2007. Revista Brasileira de Economia, v. 64, n. 2, p. 91-113, 2010.

BARRO, R.; SALA-I-MARTIN, X. Economic growth. Cambridge: The MIT Press, 2003.

BONELLI, R. Produtividade e armadilha do lento crescimento. In: DE NEGRI, F.; CAVALCANTE, L. (Org.). Produtividade no Brasil: desempenho e determinantes. Brasília: IPEA/ABDI, 2014, p. 111-142.

BONELLI, R.; BACHA, E. Crescimento brasileiro revisitado. In: VELOSO, F. (Org.). Desenvolvimento econômico: uma perspectiva brasileira. Rio de Janeiro: Campus, 2013.

BONELLI, R.; FONSECA, R. Ganhos de produtividade e de eficiência: novos resultados para a economia brasileira. Texto para Discussão 557. Rio de Janeiro: IPEA, 1998.

BONELLI, R.; VELOSO, F. Rio de Janeiro: crescimento econômico e mudança estrutural: In: PINHEIRO, A. C.; VELOSO, F. Rio de Janeiro: um estado em transição. Rio de Janeiro: Editora FGV, 2012.

BUGARIN, M.; ELLERY JR, R.; GOMES, V.; TEIXEIRA, A. The Brazilian depression in the 1980s and 1990s. 2002. Disponível em: 
http://www.economia.puc-rio.br/pdf/seminario/mirta_bugarin.pdf. Acesso: 19 mar. 2017.

BUREAU OF ECONOMIC ANALYSIS. Data. 2017. Disponível em: https://www.bea.gov/. Acesso: 22 jan. 2017.

DE NEGRI, F.; CAVALCANTE, R. Os dilemas e os desafios da produtividade no Brasil. In: DE NEGRI, F.; CAVALCANTE, R. (Org.). Produtividade no Brasil: desempenho e determinantes. Brasília: IPEA/ABDI, 2014, p. 15-52.

DENISON, E. United States economic growth. Journal of Business, v. 35, n. 2, p. 109-121, 1962.

DUMÉNIL, G.; LÉVY, D. Neoliberalismo - neo-imperialismo. Economia $e$ Sociedade, v. 19, n. 1, p. 1-19, 2007.

ELLERY JUNIOR, R. Desafios para o cálculo da produtividade total dos fatores. In: DE NEGRI, F.; CAVALCANTE, R. (Org.). Produtividade no Brasil: desempenho e determinantes. Brasília: IPEA: ABDI, 2014, p. 53-86.

FEENSTRA, R., INKLAAR, R.; TIMMER, M. The next generation of the Penn World Table. American Economic Review, no prelo.

FEIJÓ, C. A Medida de utilização de capacidade: conceitos e metodologias. Revista de Economia Contemporânea, v. 10, n. 3, p. 611-629, 2006.

FERREIRA, P.; ELLERY, R.; GOMES, V. Produtividade agregada brasileira (1970-2000): declínio robusto e fraca recuperação. Estudos Econômicos, v. 38, n. 1 , p. 31-53, 2008.

FERREIRA, P.; VELOSO, F. O desenvolvimento econômico brasileiro no pósguerra. In: VELOSO, F.; FERREIRA, P.; GIAMBIAGI, F.; PESSÔA, S. (Orgs.). Desenvolvimento econômico: uma perspectiva brasileira. Rio de Janeiro: Elsevier, 2013. p. 129-165.

GAROFALO, G.; YAMARIK, S. Regional convergence: evidence from a new state-by-state capital stock series. Review of Economics and Statistics, v. 84, n. 2, p. 316-323, 2002.

GASQUES, J; BASTOS, E.; BACCHI, M. Produtividade na agricultura brasileira. Agroanalysis, 2008. Disponível em: http://biblioteca digital.fgv.br/ojs/index.php/agroanalysis/article/viewFile/36810/35584>. Acesso: 30 out. 2017. 
GOMES, V.; PESSÔA, S.; VELOSO, F. Evolução da produtividade total dos fatores na economia brasileira: uma análise comparativa. Pesquisa e Planejamento Econômico, v. 33, n. 3, p. 389-434. 2003.

GRILICHES, Z. Productivity, R\&D, and the data constraint. In: GRILICHES, Z. $R \& D$ and productivity: the econometric evidence. Chicago: University of Chicago Press, 1998. p. 347-374.

INSTITUTO BRASILEIRO DE ECONOMIA (IBRE). Dados. Disponível em: http://portalibre.fgv.br/main.jsp?lumChannelId=402880811D8E34B9011D92BB 3D901CD7. Acesso: 15 out. 2017.

INSTITUTO BRASILEIRO DE GEOGRAFIA E ESTATÍSTICA (IBGE). Dados. 2017. Disponível em: www.ibge.gov.br/. Acesso: 12 mai. 2020.

KENDRICK, J. Productivity trends: capital and labor. Review of Economics and Statistics, v. 38, n. 3, p. 248-257, 1956.

LUCAS, R. On the mechanics of economic development. Journal of Monetary Economics, v. 22, n. 1, p. 3-42, 1988.

MANKIW, G.; ROMER, D.; WEIL, D. A contribution to the empirics of economic growth. Quarterly Journal of Economics, v. 107, n. 2, p. 407-437, 1992.

MARANGONI, G. Anos 1980, década perdida ou ganha? IPEA: desafios do desenvolvimento. Ano 9, Edição 72, 2012.

MARQUETTI, A. Progresso técnico, distribuição e crescimento na economia brasileira: 1955-1998. Estudos Econômicos, v. 32, n. 1, p. 103-124, 2002.

MENEZES-FILHO, N.; CAMPOS, G.; KOMATSU, B. A evolução da produtividade no Brasil. Policy Paper n. 12. São Paulo: Insper, 2014.

MESSA, A. Metodologias de cálculo da produtividade total dos fatores e da produtividade da mão de obra. In: DE NEGRI, F.; CAVALCANTE, L. (Org.). Produtividade no Brasil: desempenho e determinantes. Brasília: IPEA/ABDI, 2014.

MORANDI, L.; REIS, E. Estoque de capital fixo no Brasil, 1950-2002. In: Encontro Nacional de Economia, 20., 2004, João Pessoa. Anais eletrônicos... Niterói: ANPEC, 2004.

PENN WORLD TABLE. PWT 8.1. 2016. Disponível em: http://www.rug.nl/research/ggdc/data/pwt/pwt-8.1. Acesso: 22 jan. 2016. 
PESQUISA NACIONAL POR AMOSTRA DE DOMICÍLIOS (PNAD). Microdados de 2004 a 2014. 2017. Disponível em: ftp://ftp.ibge.gov.br/Trabalho_e _Rendimento/Pesquisa_Nacional_por_Amostra_de_Domicilios_anual/. Acesso: 24 jan. 2017.

ROMER, P. Endogenous technological change. Journal of Political Economy, v. 98, n. 5, p. 71-102, 1990.

ROMER, P. Increasing returns and long-run growth. Journal of Political Economy, v. 94, n. 5, p. 1002-1037, 1986.

SALA, V. Diferentes metodologias para o cálculo do produto interno bruto potencial brasileiro. 2014. 49 f. Dissertação (Mestrado em Economia) - Programa de Pós-Graduação de Economia, Fundação Getúlio Vargas, São Paulo, 2014.

SILVA, F.; MENEZES-FILHO, N.; KOMATSU, B. Evolução da produtividade no Brasil: comparações internacionais. Policy Paper n. 15. São Paulo: Insper, 2016.

SOLOW, R. A contribution to the theory of economic growth. Quarterly Journal of Economics, v. 70, n. 1, p. 65-94, 1956.

SOUZA, T.; CUNHA, M. Performance of Brazilian total factor productivity from 2004 to 2014: a sectoral and regional analysis. Journal of Economic Structures, v. 7, n. 24, p. 1-18, 2018.

SQUEFF, G.; DE NEGRI, F. Produtividade do trabalho e mudança estrutural no Brasil nos anos 2000. In: DE NEGRI, F.; CAVALCANTE, L. (Org.). Produtividade no Brasil: desempenho e determinantes. Brasília: IPEA/ABDI, 2014, p. 249-280.

SWAN, T. Economic growth and capital accumulation. Economic Record, v. 32, n. 2, p. 334-361, 1956.

\section{Financiamento}

Coordenação de Aperfeiçoamento de Pessoal de Nível Superior (CAPES).

\section{Agradecimentos}

As autoras agradecem as críticas e sugestões dos pareceristas anônimos. 